أثر استخدام استراتيجية لعب الادوار على تنمية الأكاء الاجتماعى --- محمد أحمد محمد سليم

أثر استخدام استراتيجية لعب الادوار على تنمية الذكاء الاجتماعى لاى

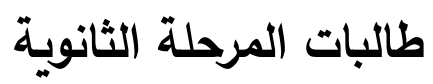

إعداد

* محمد أحمد محمد سليم

مقدمة

فى ظل التطور المعرفى تأتى أساليب التدريس الحديثة والتى تعتبر المتعلم محورالعملية

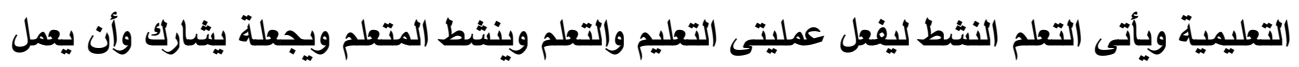

ويفكر فيما يعلمة حتى يكون قادرا على إتخاذ القرارات والقيام بالاجراءات التلازمة للتغيير والتطوير ولتير

والتقويم.

وتتبلور أهمية التعلم النشط فى أنه ينظر إلى المتعلم بعين المسئوليه عند إكتثاف

وبناء وخلق منتج تعليمى جديد، وينظر إلى المعلم على أنه مصدر وميسر، إلا أن هناك بعض النه

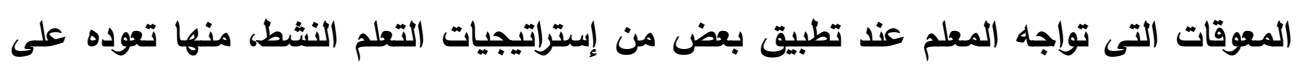
استخدام الطريقه التقليديه، وعدم الإلمام باستراتيجيات التعلم النشط المختلفه وكيفيه تطبيقها،

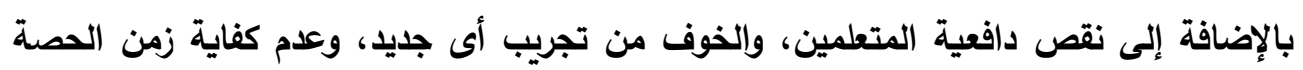
للتطبيق، وغيرها من الصعوبات التى تواجه المعلم عند التطبيق. ولقد أختار الباحث استراتيجة لعب الادوار من استراتيجيات التعلم النشط "حيث يتناول لعب الأدوار المشكلات الإجتماعية بطريقة أدائية تغرس من خلالها القيم وإكتساب الإتجاهات وتعديل السلوك الإجتماعى من خلال مواقف تحاكى مواقف الحياة فى الواقع" نعمان عبدالالسميع . ( $\{1-\varepsilon \cdot: Y \cdot 17)$

"بحث مشتق من رسالة ماجستير تحت اشراف: أ .د/عبدالناصر السيد عامر . استاذ علم النفس التربوى - كلية التربية- جامعة قناة السويس. أ ـ م .د/هالة عبداللطيف. استاذ الصحة النفسية المساعد - كلية التربية- جامعة قناة السويس.

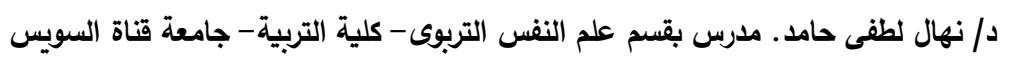




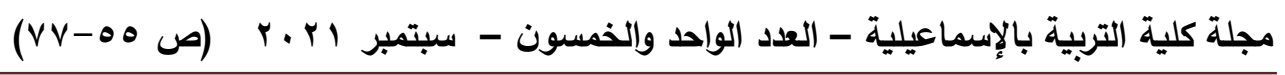
أما الأكاء الإجتماعى فان له أهميه كبيره فى حياتنا،فقد زات الحاجة الى استخدام مهارات الأكاء الاجتماعى فى القرن العشرين لكى ينجح كل انسان فى مجالات الحياة، فما أحوج الناس أيما كان تخصصهم أوعملهم أو اهتماماتهم التى يتجهون اليها، لذلك كان من الضرورئ أن نبحث عن عن هذه لانه

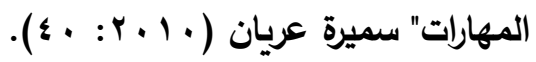
مشكلة الاراسة

من خلال عمل الباحث كمعلم لمادة علم النفس بالمرحلة الثانوية لاحظ الباحث من خلال عمله كمعلم علم النفس انخفاض التفاعل الاجتماعى لاي بعض طلاب المرحلة الثانوية، وإنخفاض قدرتهم على العمل فى مجموعات تنافسيه، وعلى فهم دوافع ومقاصد الآخرين، وعلى القيادة والتأثير فى الآخرين، مما دفع الباحث الى تجريب استراتيجية لعب الأدوار فى تدريس مادة علم النفس للمرحلة الثانوية التى قد تساعد طالبات مادة علم النفس للمرحلة الثانوية على تنمية الأكاء الاجتماعى لايهم. وفى ضوء ذلك يمكن تحديد مشكلة الدراسة فى السؤال التالي: 1 - ما أثر استخدام استراتيجية لعب الأدوار فى تنمية الذكاء الاجتماعى لدى طالبات الصف

الثالث الثانوى ؟ أهدف الدراسة هدفت الاراسة الحالية إلى ما يلى: 1 -دراسة أثر برنامـج قائم على إستراتيجية لعب الأدوار فى تنمية الذكاء الاجتماعى لاى عينة من طالبات الصف الثالث الثانوى. أهمية الدراسة تفيد الدراسة فى: 1 . ضرورة تفعيل استخدام استراتيجيات التعلم النشط وخاصة استراتيجية لعب الأدوار فى العملية التعليمية بالمسنويات التعلسيميسة المختلفة. r. اعداد دورات لمعلمات مادة علم النفس للصف الثالث الثانوى للتدريب على استراتيجية لعب الأدوار. مصطاحات الدراسة ا إستراتيجية لعب الأدوار Role Playing Strategies هى أحد استراتيجيات النعلم النشط وهى عبارة عن خطة من خطط المحاكاة فى موقف يشابة الموقف التعليمى، حيث يتقمص المتعلم أحد الأدوار التى توجد فى الموقف الواقعى، ويتفاعل مع 
أثر استخدام استراتيجية لعب الادوار على تنمية الأكاء الاجتماعى --- محمد أحمد محمد سليم

الآخرين بفاعلية، وتعتبر هذه الطريقة ذات أثر فعال فى مساعدة الطلاب على فهم أنفسهم وفهم الأخرين، وهى تتميز كذلك بأنها تخلق فى الفصل تفاعلاً أكثر إيجابيه وحيويه. Social Intelligence الأكاء الإجتماعى لونى

يثير إلى قرة الفرد على إدراك أمزجة الآخرين ومقاصدهم ودوافعهم ومشاعرهم والتمييز بينهم فى المواقف المختلفة بوضوح مع القدرة السلوكية على التصرف بتعاطف وتعاون وحكمة ولباقة مع الأخرين مما يكسب الفرد القدرة على القيادة والتأثيرفى الآخرين ويفتح الأفق

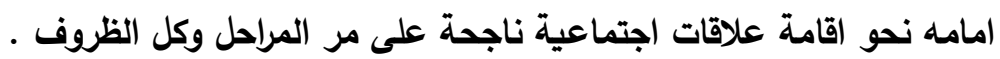

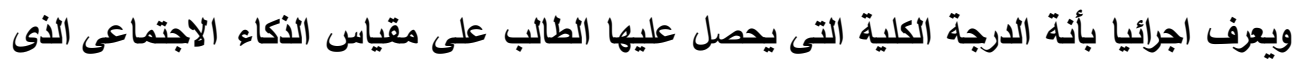

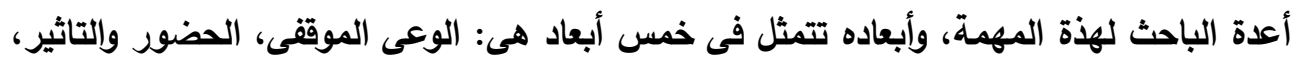
الوضوح، التعاطف، المهارات الاجتماعية. الإطار النظرى والدراسات السابقة

وزعت الجوانب النظرية التي تخص متغيرات البحث الحالي على محورين: يتناول المحور الأول استراتيجية لعب الأدوار ، والمحور الثانى الأكاء الإجتماعى.

Role Playing المحور الأول: إستراتيجية لعب الأدوار يعتبر أسلوب لعب الأدوار من الأساليب التى تتصف بمحاكاة الواقع ويقوم على تمثيل بعض الحوادث والأدوار الواقعية المهمة عن طريق العرض وإثارة الإنتباة، وفيه يقوم المعلم بإعداده بثكل مسبق قبل شرح درس ما وذلك بتوزيع الأدوار على طلابه وبطلب منهم أن يستعدوا لتمثيل هذه الأدوار فى الدرس القادم، والطالب هو صاحب الدور الرئيس فى هذه الطريقة، أو بإمكانة تكليفهم أثناء الدرس إذ لم يكن الموضوع يحتاج إلى تحضير مسبق.

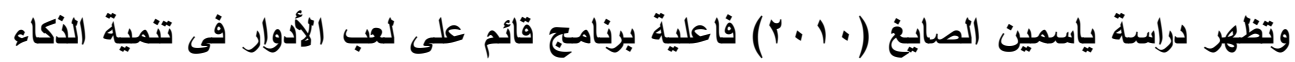

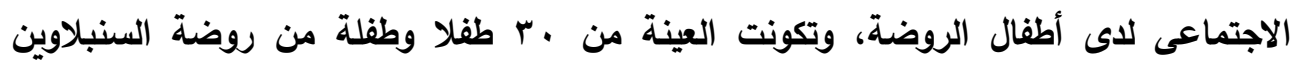
التجرببية للغات، وقد أسفرت النائج وجود فروق دالة احصائيا بين درجات متوسطات درجات الترات أطفال المجموعة الضابطة والمجموعة التجريبية فى القياس البعدى على مقياس الأكاء الاجتماعى المصور لصالح المجموعة التجريبية. ا - الاجعريف الإستراتيجية

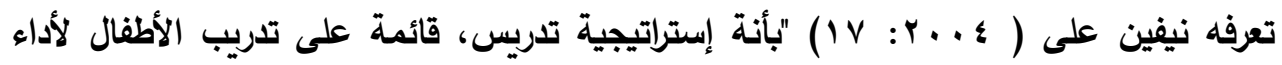
أدوار شخصيات بشكل محدد من خلال نص سبق إعدادة لمواقف تحاكى المواقف الواقعية، 


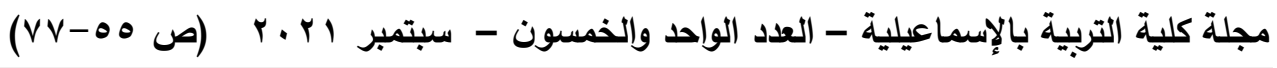
تتضمن مشكلات مستهرف حلها، وفيها يتفاعل الأطفال مع بعضهم البعض،تنتهى بالمناقشة بين المعلمة والأطفال عن طبيعة الأدوار التى تم أدائها وملاحظتها، بهدف الوصول إلى حلول لمواقف لهف

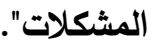

ويعرفه الباحث بأنة خطة من خطط المحاكاة فى موقف يثابة الموقف التعليمى، حيث يتقص المتعلم أحد الأدوار التى توجد فى الموقف الواقعى، ويتفاعل مع الآخرين فى علاقة دوره بأدوارهم،

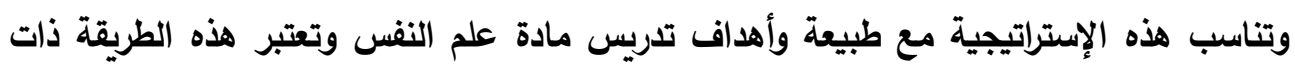
أثر فعال فى مساعدة الطلاب على فهم أنفسهم وفهم الأخرين، وهى تتميز كذلك بأنها تخلق فى هلى الفصل تفاعلاً أكثر إيجابية وحيوية مما يخلق جو اجتماعى مبهج. r - خطوات التدربب على المهارة ياسلوب تمثيل الأدوار: "فيما يلى مجموعة من الخطوات الأساسية المقترحة والتى يمكن من خلالها تطبيق أسلوب تمثيل الأدوار للتدريب على المهارة التدريسية منها :

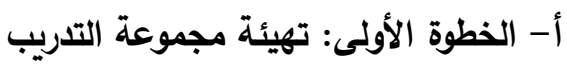
وتتم من خلال قيام المشرف على التدريب بإعطاء مجموعة التدريب خلفية معرفية نظرية عن مهاره التدريب من أهميتها ومكوناتها السلوكية وأساليب ملاحظتها وقياسها وكذلك قيامه بإعطائهم فكرة عن كيفية التدريب على ذلك الأسلوب . ب- الخطوة الثانية: توزيع الأدوار بمقتضاها يتولى المشرف على التدريب توزيع الأدوار على أفراد مجموعة التدربب،بحيث يختار من يقوم بدور المعلم (البطل) وهو المتدرب على المهارة، ومن يقوم بدور الطلاب المشاركين مباشرة فى الموقف التدريسى وهم المثثلون المساعدون، ومن يقوم بدور بقية الطلاب فى الصف وهم المشاهدون (المتفرجون). ج- الخطوة الثالثة: تهيئة المسرح ويتم ذلك بقيام المشرف و الطلاب بإعداد غرفة التدريب وتجهيزها. د- الخطوة الرابعة: التمثيل وبمقتضى ذلك تقوم مجموعة التدريب بتنفيذ السيناريو سالف الذكر. هـ - الخطوة الخامسة: النقد

ويتم عقب التمثيل مباشرة وفية يتم أساساً الإستماع إلى ملاحظات المشاهدين وإرائهم و كذا أراء المشرف على التدريب وملاحظاتة حول مدى جودة أداء البطل لسلوكيات المهارة وكيفية تحسين 
أثر استخدام استراتيجية لعب الادوار على تنمية الأكاء الاجتماعى --- محمد أحمد محمد سليم

هذا الأداء وكذلك حول مدى دقة قيام الممثلين المساعدين لأدوارهم وكيفية تحسين أدائهم لتلك الأدوار. ى - الخطوة السادسة: أعادة التمثيل والنقد وفيها تكرر الخطوتان الرابعة والخامسة سالفة الأكر، وحتى يتقن البطل مهارة التدربس محل

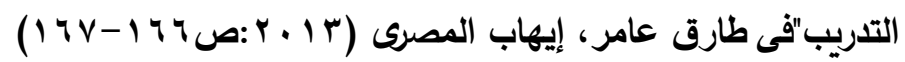

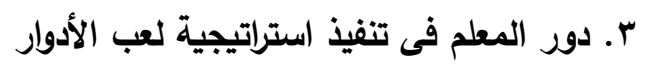

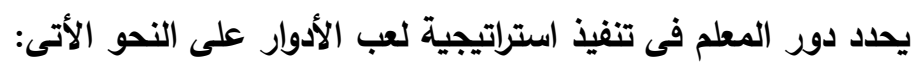

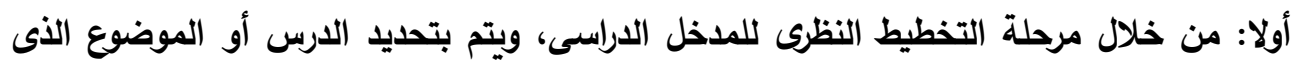
يمكن تنفيذه وفقاً للمدل الدراسى، ثم الإطلاع على محتوى الدرس لتحديد مواطن الصعوبة والسهولة فى الدرس، وتحديد أهداف الدرس، المعلومات والمفاهيم والمهارات المتضمنة فى هي الدرس، وتحديد الوسائل التعليمية والأنثطة التعليمية المكملة للنشاط التمثيلى وتحديد أساليب التقويم المناسبة. ثانياً:من خلال مرحلة التطبيق العملى للمدخل الدراسى ويتحدد دور المعلم فى هذه المرحلة فى

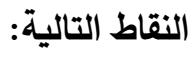
أ- تهيئة و تنشيط التلاميذ لعملية التمثيل. ب- عرض موضوع الارس توزيع الأدوار على التلاميذ. ج- إعطاء التوجيهات للتلاميذ المشاركين و المشاهدين. د - القيام بعملية التمثيل.

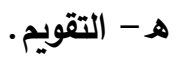

وقد أظهرت دراسة أحمد سليمان (Y. PV) فاعلية برنامج قائم على تنويع الأنثطه التعليميه باستخدام توزيع الأدوار فى تدريس علم الإجتماع لتنمية الذكاء الإجتماعى لاى طلاب المرحلة

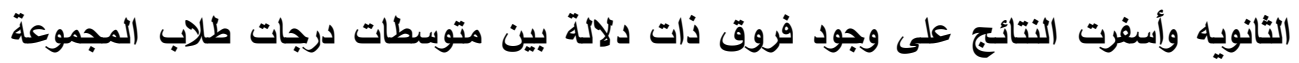
التجريبية فى مقياس الأكاء الاجتماعى لصالح التطبيق البعدى. ع. مستويات تطبيق استراتيجية لعب الأدوار "تنقسم مستويات التطبيق إلى عدة مستويات منها: المستوى الأول: يطلب المعلم من المتعلم أن يتخيل نفسة أحد الثخصيات التى يدرسها، ويعبرعن إحساس هذه الشخصيات التى يدرسها، ويعبرعن إحساس هذه الثخصية فى موقف من المواقف الثفي 


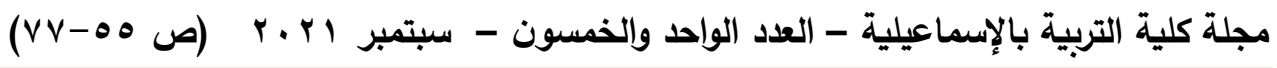
كما يتوقعة هو، فإتاحة هذه الفرصة للمتعم فى أن يضع نفسة مكان إحدى الشخصيات ويعبرعن أحساسها من وجهة نظرة تبعث الحياة فى هذه الثخصيات وتزبد من حيوية الموقف التعليمى. المستوى الثانى: وفيه يقوم المتعلم بتمثيل الدور أو الموقف التاريخى أو الإجتماعى أو العلمى لهیه الأى يدرسة حيث توزع الأدوار على المتعلمين وتعطى لهم فترة زمنية محددة للإستعداد ثم يقومون بأداء المشهد أمام زملائهم. وقد أوضحت دراسة مكارثى و أندرسون(Mccarthy\&Anderson,2000) "أثر التعلم النشط بأساليب متنوعة بما فيها أسلوب لعب الأدوار الجمعى والأنشطة التعليمية التعاونية فى تمثيل

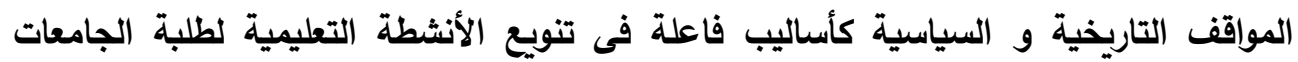
بإقسام التاريخ والعلوم السياسية واستقصاء تأثيرها على التحصيل الدراسى لطلبة الجامعات مقارنة مع أساليب التدريس التقليدية،و أظهرت نتائج الدراسة أن الطلبة الذين تعلموا بإستخدام التعلم النشط أحرزوا نتائج أفضل من أقرانهم الذين تعلموا بإستخدام أساليب التدريس التقليدية فى الإختبارات التحصيلية و أختبارات تقييم الأداء. المستوى الثالث: وهو قيام المتعلمين بتمثيل المشهد، والذى يمكن أن يكون معبراً عن حياة أسره

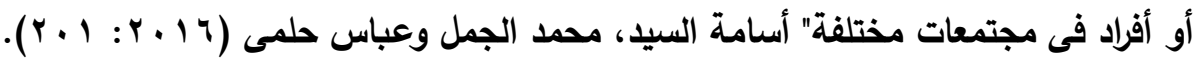

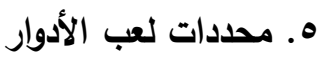
"من أبرز محددات التدريب بأسلوب تمثيل الأدوار مايلى:

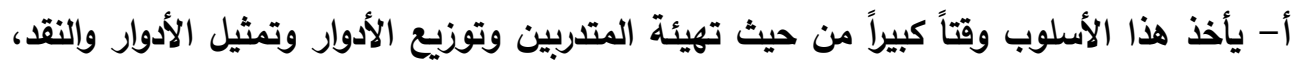
واذا لم يتم توفير الوقت الكافى اللأزم لألك فإن المزايا المرجوه من استخدام هذا الأسلوب تكون عرضة للضياع. ب- فى حالة عدم توافر مشرف كفء فاهم هذا الأسلوب وكيفية تطبيقه فى التدريب، فإن هذا الأسلوب يكون مضيع للوقت بل أنة فى أسوء الظروف قد هيكون محطماً للمتدربين وغير مفيد ج- إذا لم يأخذ المتدربون الأمر بالجدية الكافية، فإنة قد يرون التدريب وفق هذا الأسلوب نوعاً من التسلية لا أكثر ولا أقل. د - قد يجد بعض المتدربين من ذوى الثخصيات المنطوية أو الخجولة صعوبة فى تقبل هذا

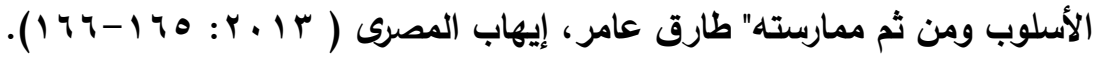

$$
\begin{aligned}
& \text { 7. مميزات استخدام استراتيجية لعب الأدوار فى التدريس: } \\
& \text { "لهذه الطريقة مميزات عدة منها أنها: }
\end{aligned}
$$


أثر استخدام استراتيجية لعب الادوار على تنمية الأكاء الاجتماعى --- محمد أحمد محمد سليم

* تزيد الدافع والحافز للتعليم والإقبال علية،لأنها تجذب الإنتياة لكونها خروجاً عن المألوف أثناء

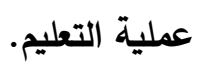
* تشجع هذه الطريقة وبخاصة ما يتعلق منها بأنشطة المحاكاة عمليات التحليل والتفكير لاى

$$
\text { الطالب. }
$$

* تعد طريقة جديدة يتم من خلالها اكتساب القيم والسلوكيات الحسنة.

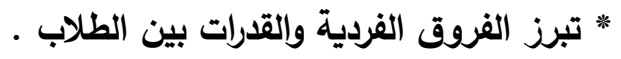

* تعود الطلاب النظام والألتزام ومراعاة الترتيب والإنصات،وأدب الحوار، إذ ينتظر حتى يفرغ من أمامة من كلامة، ويلتزم بما حدد له من أداء وأن يتناول ما حدد لله من حوار. * تعد وسيلة معينة فى حل مثكلات الدارسين النفسية، اذ تعودهم على المثاركة والتعاون

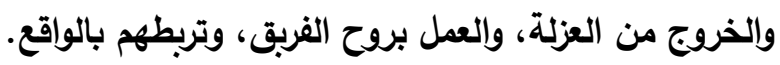
* يراعى المعلم أن تتضمن المشهر التمثيلى شيئاً من الدعابة، حتى يضفى ولى على الموضى الموضوع حيوية وبهجة. * بعد الإنتهاء من أداء المشهر التمثيلى يناقش المعلم مع الدارسين ما جاء فيه، ويطرح عليهم أسئلة للتأكد من تحقيق الأهداف التربوية التى حددها سلفا فى ضوء المعايير.

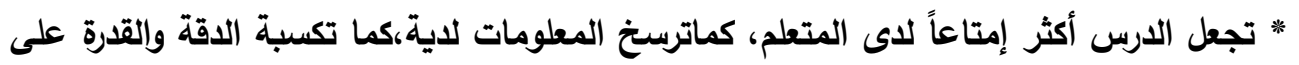

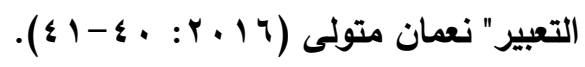

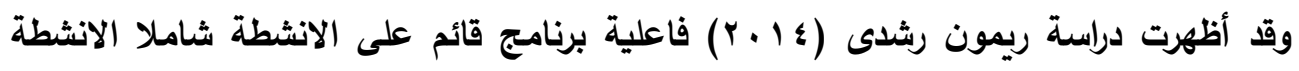
التمثيلية للشخصيات التاريخية لتنمية الأكاء الاجتماعى لاعى تلاميذ المرحلة الاعدادية والميل

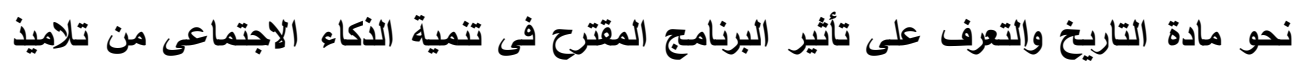
الصف الاول الاعدادى بمحافظة القاهرة، وقد أسفرت النتائج على وجود فروق ذات دات دلائة بين متوسطات درجات طلاب المجموعة التجريبية فى مقياس الذكاء الاجتماعى لصالح التطبيق البعدى . 1 إن

$$
\text { V }
$$

على الرغم من طريقة لعب الأدوار لها مميزات إلا أنها يوجد بها عدة عيوب تتمثل فى الأتى : * تحتاج أحياناً إلى إعداد مسبق ومطول، وتعم الفوضى فى الفصل أن لم تطبق بعناية وحزم. * تحتاج فى بعض المواقف إلى أدوات وتجهيزات مسبقة قد تكون مكلفة. * إذا لم يوزع المعلم الأدوار بثكل مرضى ومقنع فقد يعتقد الطالب بتحيز المعلم. 


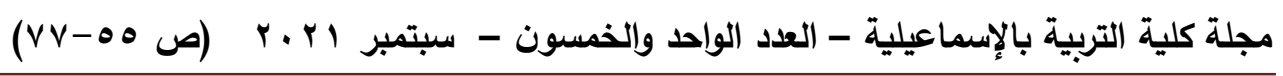
* لا تلائم كثيراً من الموضوعات، كما أنها تحتاج لجه كبير فى إعدادها وتدربب المتعلمين

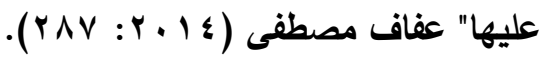
تعقيب:

تم الاستفادة من عرض استراتيجية لعب الأدوار فى اعداد أنثطة للبرنامج تعمل على تطبيق هذه الاستراتيجية بصورة عملية فى الواقع التربوى (مثل تعلمى من العظماء -استرجعى ذكريات طيبةأظهرى موهبتك- أجعلى لكى نموذج- أتعلمى من قصص الناس- التمثيل الصامت-حاكى المفاهيم - معلمة المستقبل - المثال الثارح).

\section{Social Intelligence}

$$
\text { تعريف الأكاء الاجتماعى الإجتماعى: الأكاء الاجتماعى }
$$

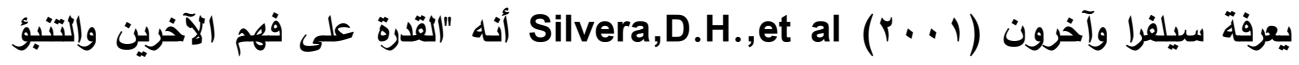
بردود أفعالهم فى المواقف الإجتماعية المختلفة (Silvera,D.H.,et a,2001:313-319). ويعرفة الباحث بأنة قدرة الفرد على إدراك أمزجة الآخرين ومقاصدهم ودوافعهم ومشاعرهم والتمييز بينهم فحى المواقف المختلفة بوضوح مع القدرة السلوكية على التصرف بتعاطف وتعاون وحكمة ولباقة مع الأخرين مما يصنع لاى الفرد القدرة على القيادة والتأثير ويفتح الأفق امامه نحو اقامة علاقات اجتماعية ناجحة على مر المراحل وكل الظروف. ثانياً: أبعاد الأكاء الإجتماعى: هناك العديد من الآراء التى تناولت أبعاد الأكاء الإجتماعى منها ماءئ يلى:

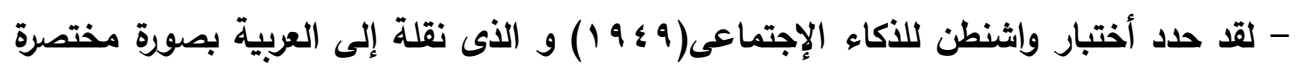
محمد عماد الدين إسماعيل و سيد عبد الحميد مرسى (1900) ثم نقلة إلى العربية بصورتة الكاملة حسين الاربنى ( • 9 1 ) الأبعاد التالية: أ. القدرة على إصدارالأحكام فى المواقف الإجتماعية ( أى القدرة على التصرف فى المواقف (الإجتماعية). ب. القدرة على التعرف على حالة المتكلم النفسية من العبارات التى يقولها. ج. القدرة على تذكر الأسماء و الوجوة. د. القدرة على ملاحظة السلوك الإنسانى.

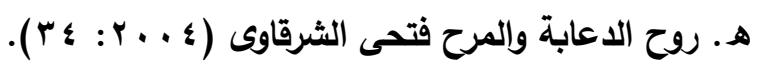


أثر استخدام استراتيجية لعب الادوار على تنمية الأكاء الاجتماعى --- محمد أحمد محمد سليم

وقد خلصت دراسة ضمياء إبراهيم، أحلام مهدى( • ( + ب) التى درست الأكاء الإجتماعى وعلاقتة

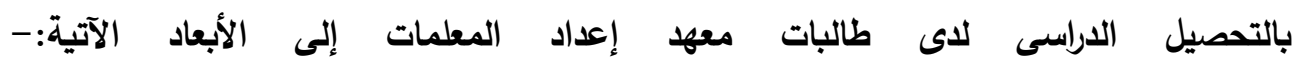
أ- الوعى الموقفى:وهو القدرة على قراءة الموقف وإصدار الأحكام والتصرف فئى المواقف الإجتماعية وتفسير سلوكيات الآخرين فى تلك الموقف. ب- الحضور والتأثير: تضم مجموعة كاملة من الإثارات التى يعالجها الآخرون. ج- الوضوح: وهو القدرة على تفسير أفكارك وصياغة آرائك بسلاسة. د - التعاطف: إحساس مشترك بين شخصين.

هـ - المهارة الاجتماعية: وهو مجموعة من السلوكيات اللفظية والغير لفظية. وقد أختار الباحث هذه الأبعاد لتصميم مقياس من إعداده لقياس الأكاء الإجتماعى. وهذه الأبعاد متفقة مع نموذج rarl Albecht"' الأنى قدمة فى كتابة "الأكاء الإجتماعى علم النجاح الجديد،(الوعى الموقفى -الحضور -الوضوح-التعاطف) "كارل البريخت .$"(r, \mid r)$ تعليق عام على الاطار النظرى و الدراسات السابقة بناء على ما تم استعراضة فى الاطار النظرى و الدراسات السابقة أتضح ما ليلى:

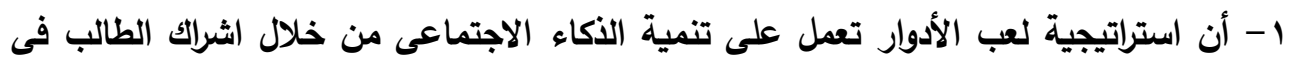

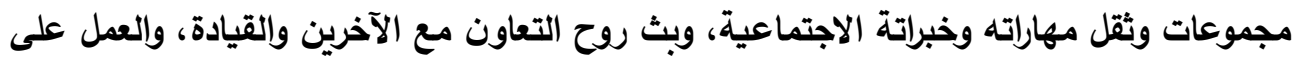

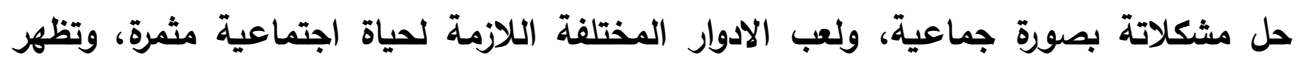

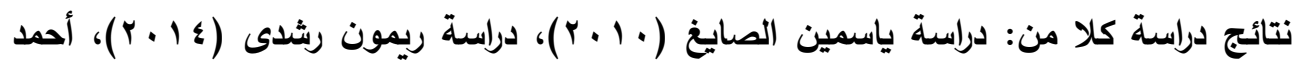

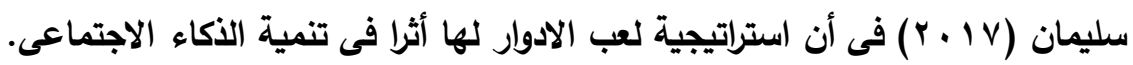

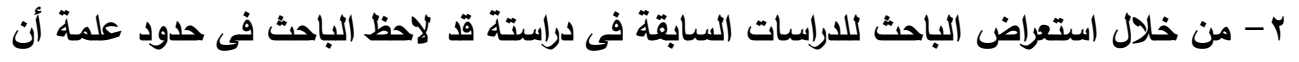

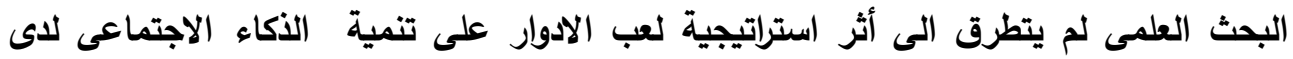
طالبات المرحلة الثانوية وقد نبع ذلك فى احساس الباحث بمثكلة الدراسة. فروض الاراسة: فى ضوء الاطار النظرى و الدراسات السابقة، و طبيعة مشكلة الدراسة الحالية تطرح فروض الدراسة كما يلى الفروض البحثية 1 - يوجد أثر للبرنامج القائم على إستخدام بعض استراتيجية لعب الادوار فى تنمية الذكاء الاجتماعى لاى عينة من طالبات المرحلة الثانوية. 


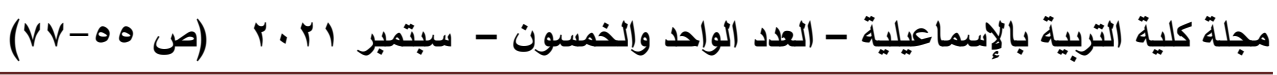
الفروض الإحصائية

1- توجد فروق داله احصائياً بين متوسطى درجات طالبات المجوعة التجريبية والمجوعة الضابطة فى القياس البعدى لمقياس الأكاء الاجتماعى لصالح المجوعة التجريبية. منهج الاراسة واجراء اتهاء أولاً: منهج الدراسة والأساليب الاحصائية: تم استخدام المنهج شبه التجريبى ذو المجموعتين قبلى وبعدى (مجموعة ضابطة ومجموعة تجريبية )؛ وذلك لأنه مناسب لههف الدراسة وهو التعرف على فعالية استراتيجية لعب الأدوار فى تنمية الأكاء الاجتماعى.

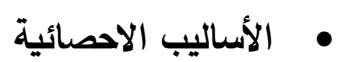

استخدم الباحث الأساليب الاحصائية الآتية:

1 - أختبار ت المستقلة: للتحقق من تكافؤ المجموعات التجريبية والضابطة فى العمر،التحصيل الدراسى والذكاء الاجتماعى، وفى القياس البعدى للتحقق من الفروق بين المجموعة التجريبية والمجموعة الضابطة فى القياس البعدى للتحصيل الاراسى والذكاء الاجتماعى. r - مؤشر ايتا تربيع: لحساب حجم التأثير.

ثانياً: التصميم التجريبي: Experimental design

\begin{tabular}{|c|c|c|c|c|}
\hline قياس بعدى & المتغيرات & قياس قله & عدد العينة & المدمه عة \\
\hline الذكاء الاجتماعى & برأدنامج قائم على استراتيجية لعب & الإجتماءعى الاءع & 10 & التجريبية \\
\hline الذكاء الاجتماعى & الذكاء الاجتماعى (متغير تابع) & الاجتماءع & 10 & الضانطة \\
\hline
\end{tabular}

ثالثاً: مجتمع البحث وعينته:

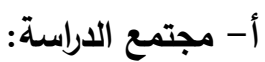

تكون مجتمع الاراسة من ( . ــ) طالبة من طالبات الصف الثالث الثانوى الادبى بالمدارس

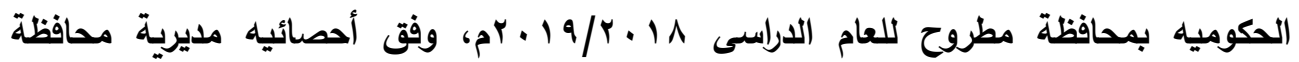

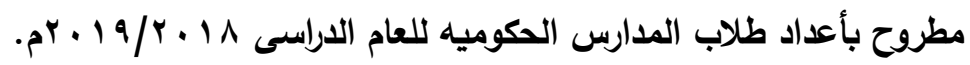

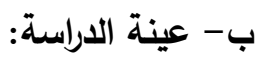
قسم الباحث عينة البحث على قسمين هما:- 
أثر استخدام استراتيجية لعب الادوار على تنمية الأكاء الاجتماعى --- محمد أحمد محمد سليم

- عينة التحقق من الخصائص السيكومترية

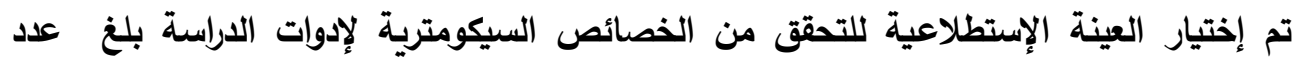

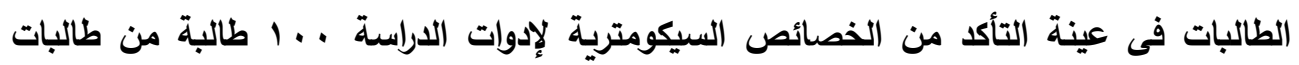

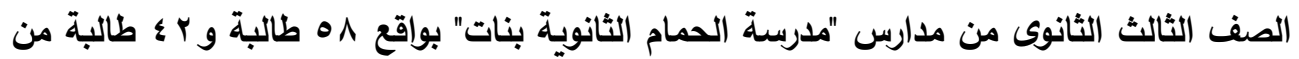

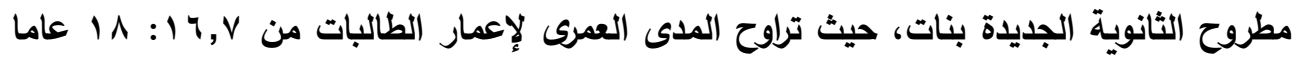

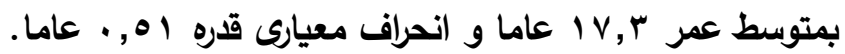

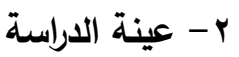

بلغ عدد الطالبات فى عينة التطبيق النهائى لإدوات الدراسة . ب طالبة من طالبات الصف الثالث الثانوى بمدرسة طه ساطور الثانوية بنات من منخفضى الأكاء الاجتماعى (من أختبار الأكاء الاجتماعى المطبق عليهم)،وانقسمت عينة الدراسة الى(10 طالبة فى المجموعة التجريبية) و(0 إلبة فى المجموعة الضابطة). رابعاً: تكافؤ المجموعات يرى الباحث ان متوسط العمر للمجموعتين التجريبية والضابطة متقارب وقد قام الباحث بالتحقق من تكافؤ المجموعتين التجريبية والضابطة فى القياس القبلى من خلال العمر، الذكاء، التحصيل الدراسى والذكاء الاجتماعى باستخدام اختبار ت التجريبية والضابطة ويبين جدول (r) متوسط درجات الطلاب لاى المجموعتين التجريبية والضابطة وقيمة ت لالالة

\begin{tabular}{|c|c|c|c|c|c|c|c|c|}
\hline \multirow{2}{*}{ مستوى الدلانة } & \multirow{2}{*}{ الحرية } & \multirow{2}{*}{ قيمة } & \multirow{2}{*}{ قالمة } & \multicolumn{2}{|c|}{ المجموعة التجريبية } & \multicolumn{2}{|c|}{ المجموعة الضابطة } & \multirow{2}{*}{ /المتغير / / / / / / / } \\
\hline & & & & المعيارى & الحسابى & الانعراف & الحسابى & \\
\hline غير دالة & YA & $Y, £ V$ & $\cdot, 91$ & $\cdot, \circ \mathrm{V}$ & $i v, r$ & & $\mid v, 1$ & العمر \\
\hline غير دالة & r^ & $r, \leqslant V$ & $\cdot, I V$ & $0, r v$ & Ir,r & & Ir, q & التحصيل الدراسى \\
\hline \multicolumn{9}{|c|}{ أبعاد الذكاء الاجتماعى } \\
\hline غير دالة & rA & $Y, £ V$ & $\cdot, 1$ & r,r & $9, \wedge 9$ & זד, צ & q, $\vee ०$ & الوعى الموقفى \\
\hline غير دالة & rA & $r, \leqslant V$ & . & r, ro & 9,1 & $\varepsilon, \leqslant 0$ & $\Lambda, \vee 1$ & الحضور والتأثير \\
\hline غير دالة & rی & $r, \leqslant V$ & $\cdot, r$ & $r, r_{1}$ & $\Lambda, \vee q$ & & $\Lambda, \diamond$ & الوضوح \\
\hline غير دالة & $r \wedge$ & $r, \varepsilon V$ &., 14 & $r, I r$ & 9,71 & $\varepsilon, 7 V$ & $q, \leqslant r$ & التعاطف \\
\hline
\end{tabular}




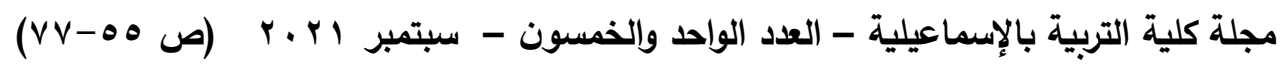

\begin{tabular}{|c|c|c|c|c|c|c|c|c|}
\hline غير دالة & $r \wedge$ & $r, \leqslant V$ & $\cdot, \cdot r \leq$ & Y,07 & $q, r$. & $\varepsilon, V r$ & $9,1 \leqslant$ & الاجتماعية \\
\hline غير دالة & $r \wedge$ & $r, \leqslant V$ & $\cdot, \pi$ & $11, \varepsilon$ & $7, \ldots, 1$ & Tr, & $\Delta V, T \leq$ & الدرجة الكلية \\
\hline
\end{tabular}

خامساً: أدوات الدراسة

اولا : مقياس الأكاء الاجتماعى ·

الهدف من بناء المقياس: قياس الأكاء الاجتماعى لاى طالبات الصف الثالث الثانوى.

التعريف الاجرائى للأكاء الاجتماعى لاى طالبات الصف الثالث الثانوى :

الارجة التى يحصل عليها الطالبات على مقياس الأكاء الاجتماعى،الذى أعدة الباحث لهذة

المهمة.

وصف مقياس الأكاء الاجتماعى

تكون المقياس فى صورته النهائية من خمس مكونات كل مكون يتكون من 1 عبارات كل

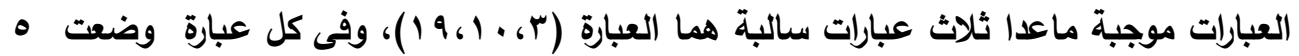
بدائل(دائما، غالبا، أحيانا، نادرا، مطلقا) حيث دائماً تعنى إنطباق العبارة على الفيات الفرد بشكل كامل،وغالبا تعنى إنطباق العبارة على الفرد فى أغلب الأوقات، أحيانا تعنى إنطباق العبارة على

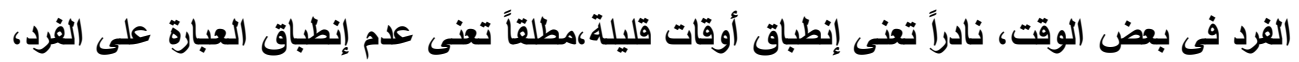

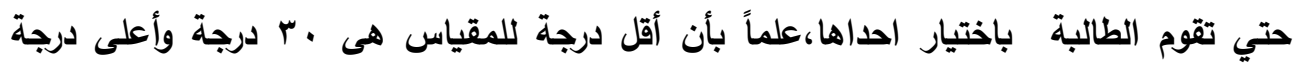

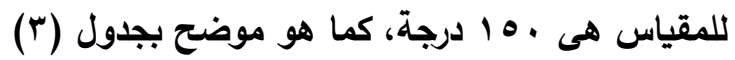
جدول (r) وصف مقياس الذكاء الاجتماعى موصع

\begin{tabular}{|c|c|c|c|}
\hline أرقام العبارات & عدد العبارات & تعريف البعد & البعد \\
\hline$r \Lambda-r r-1 q-11-q-1$ & 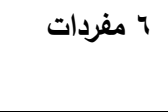 & 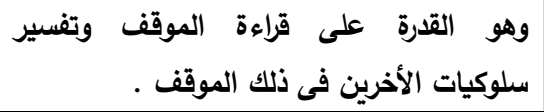 & الوعى الموقفى \\
\hline$r q-Y 0-Y \leqslant-10-V-r$ & 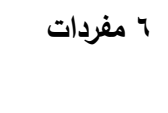 & 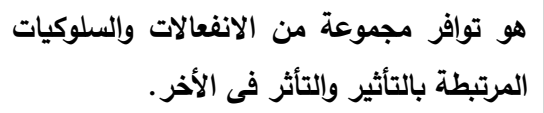 & الحضور والتأثير \\
\hline$r V-r r-1 \Lambda-1 r-\Lambda-r$ & 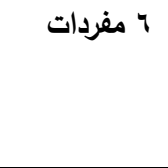 & 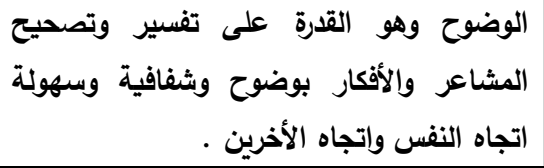 & 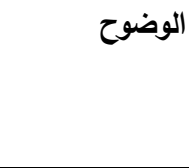 \\
\hline$r \cdot-r q-1 q-1 r-q-\varepsilon$ & 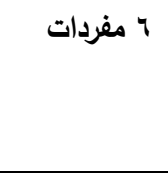 & 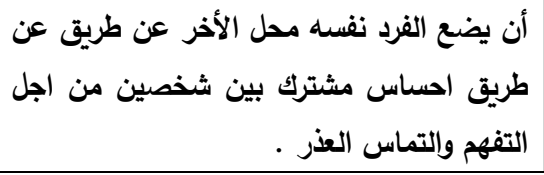 & التعاطف \\
\hline$r 1-r \cdot-1 V-1 \leq-V-0$ & 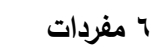 & المهارات الاجتماعية : مجموعة السلوكيات & 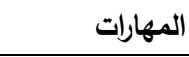 \\
\hline
\end{tabular}


أثر استخدام استراتيجية لعب الادوار على تنمية الأكاء الاجتماعى --- محمد أحمد محمد سليم

\begin{tabular}{|c|c|c|c|}
\hline & & اقامة علاقات اجتماعية ناجحة. اللفظية تمكن الفرد من & الاجتماعية \\
\hline
\end{tabular}

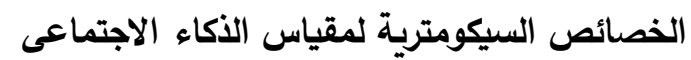

1-الصدق

صدق المحتوى

تم عرض المقياس فى صورته الاولية على مجموعة من المحكمين المتخصصين فى مجال التربية وعلم النفس والاحصاء لإبداء وجهة نظرهم فى مدى مناسبة المفردات لكل محور، وتعديل أو حذف أو اضافة أى تغييرات على مفردات المقياس، وذلك لمعرفة ارتباط كل مفردة بالمحور الأى تقيسه ومدى مناسبة صياغة كل مفردة ؛حيث اقر المحكمين ملائمة جميع المفردات

للمحاور التى تنتمى إليها.

r

قام الباحث بالتحقق من ثبات بطريقة ألفا كرونباخ لاستخدام تدريج ليكرت الخماسى فى الاجابة على مفردات المقياس ، جدول(؛) يوضح قيم معاملات الثبات الفرعية والكلية لمقياس الأكاء الاجتماعى ويرى الباحث ان قيم معامل الثبات بطريقة ألفا كرونباخ اعلى من V, • لذا فجميع

المعاملات جيدة

وتلدل على ثبات مناسب للمقياس.

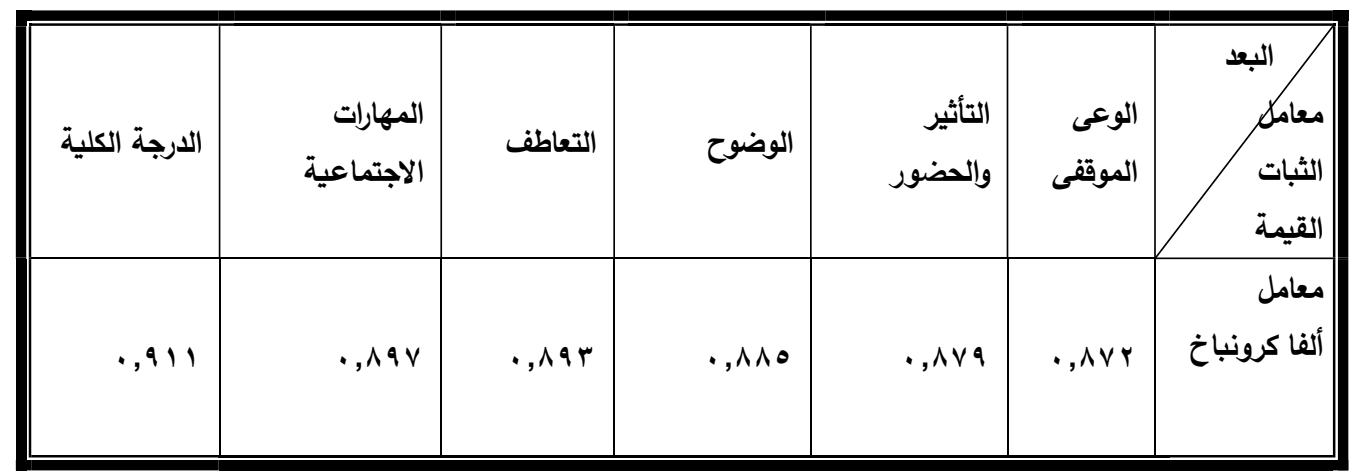

ويبين جدول رقم (؛ ) قيم معاملات الثبات الفرعية والكلية لمقياس الذكاء الاجتماعى

الاتساق الداخلى

الاتساق الداخلى بين مفردات مقياس الأكاء الاجتماعى والأبعاد التى تنتمى إليها حيث قام الباحث بالتحقق من الاتساق الداخلى لمفردات مقياس الذكاء الاجتماعى والأبعاد التى تنتمى إليها 


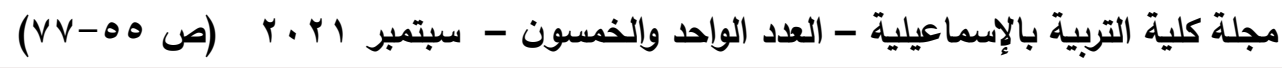
بحساب معاملات الارتباط بين مفردات المقياس والأبعاد تنتمى إليها ، كما هو موضح بجدول (0) التى (ن)

\begin{tabular}{|c|c|c|c|c|c|c|c|c|c|}
\hline & الاجتماعية & & التعاطف & & الوضوح & & والتأثضر & & الموقفى \\
\hline القيمة & رقم المفردة & القيمة & رقم & القيمة & رقمث & القيمة & رقمر & القيمة & رقم \\
\hline$\cdot, V \leqslant V$ & ro & 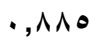 & 19 & $\cdot, \wedge 19$ & 14 & 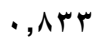 & v & • & 1 \\
\hline$\cdot, \wedge 19$ & ץ & $\cdot, \mathrm{V} \leqslant \mathrm{V}$ & $r$. & •, & $1 \leqslant$ & $\cdot, \wedge \wedge \bullet$ & $\wedge$ & •, VTr & r \\
\hline r & TV & $\cdot, \wedge 19$ & r) & • VYT & 10 & $\cdot, V \leqslant V$ & 9 & •, VIY & $r$ \\
\hline •,VYT & YA & • & rY & • & 17 & $\cdot, 119$ & 1. & • VTr & $\varepsilon$ \\
\hline צ', & rq & • VYT & rr & $\cdot, \mathrm{V} \leqslant 0$ & IV & r, vir & 11 & $\cdot, V \leqslant 0$ & 0 \\
\hline$\cdot, v \leqslant 0$ & $r$. & י & $r \varepsilon$ & $\cdot, \wedge 19$ & 11 & • • & Ir & $\cdot, \mathrm{V} \leqslant \mathrm{V}$ & 7 \\
\hline
\end{tabular}

ويرى الباحث ان قيم معاملات الارتباط بين المفردات والابعاد التى تنتمى إليها من خلال القيم

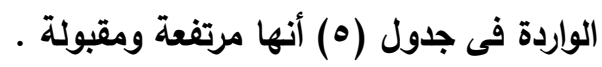
الاتساق الداخلى بين مفردات مقياس الأكاء الاجتماعى واللارجة الكلية للمقياس قام الباحث بالتحقق من الاتساق الداخلى لمفردات مقياس الأكاء الاجتماعى وإلارجة

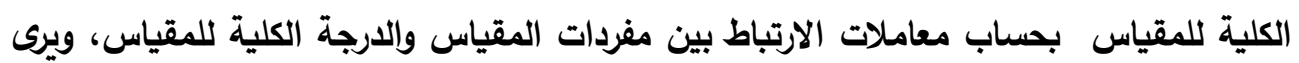
الباحث ان قيم معاملات الارتباط بين المفردات واللارجة الكلية للمقياس أنها مرتفعة ومقبولة . الاتساق الداخلى بين أبعاد مقياس الأكاء الاجتماعى والدرجة الكلية للمقياس قام الباحث بالتحقق من الاتساق الاخلى لإبعاد مقياس الأكاء الاجتماعى والدرجة الكلية بحساب معاملات الارتباط بين أبعاد المقياس واللارجة الكلية للمقياس، كما هو موضح بجدول

جدول (7) قيم معاملات الارتباط بين أبعاد المقياس والدرجة الكلية للمقياس

\begin{tabular}{|c|c|c|c|c|}
\hline المهارات الاجتماعية & التعاطف & الوضوح & الحضور والتأثير & الوعى الموقفى \\
\hline$\cdot, \wedge 91$ & $\cdot, \wedge \wedge \diamond$ & $\cdot, \wedge \wedge 1$ & $\cdot, \wedge \vee q$ & $\cdot, \wedge \vee \gamma$ \\
\hline
\end{tabular}

يرى الباحث ان قيم معاملات الارتباط بين الأبعاد والدرجة الكلية للمقياس من خلال القيم الواردة فى جدول (†) أنها مرتفعة ومقبولة . 
أثر استخدام استراتيجية لعب الادوار على تنمية الأكاء الاجتماعى --- محمد أحمد محمد سليم ثالثا: برنامج قائم على بعض استراتيجيات التعلم النشط (اعداد/الباحث ) الهدف من بناء البرنامج :

قياس أثر إستخدام استراتيجية لعب الأدوار على الأكاء الإجتماعى لاءى طالبات الصف الثالث الثانوى بالقسم الأدبى. خطوات بناء برنامج قائم على بعض استراتيجيات التعلم النشط:

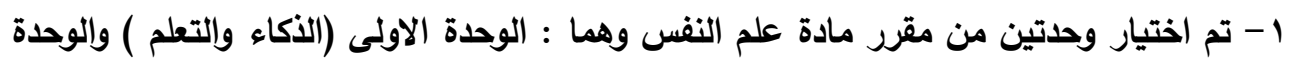

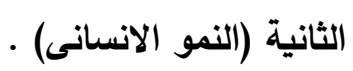
r - اعادة صياغة الوحدتين لتلائم استراتيجيات التعلم النشط. r- عرض الاليل على السادة المحكمين والمتخصصين فى مجال علم النفس التربوى لإبداء ارائهم وإقتراحاتهم بالنسبة للاليل. ء - التجربة الاستطلاعية للاليل للوقوف على الصعوبات التى تواجه تطبيقه من حيث زمن الجلسة والمحتوى والوسائل التعليمية المستخدمة فى الجلسات. ه - تعديل الاليل فى ضوء أراء السادة المحكمين وفى ضوء التجربة الائه الاستطلاعية.

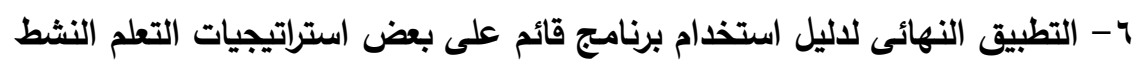
اجراءات الدراسة ا- قام الباحث باستخدام المنهج شبه التجريبى تصميم المجموعات المتكافئة للتحقق من فعالية بعض أثر التعلم النشط على التحصيل الدراسى والذكاء الاجتماعى. ץ- تصميم برنامج لبعض استراتييجية لعب الادوار على وحدتين من مقرر مادة علم النفس هما: العمليات المعرفية والنموالانسانى، اختبار تحصيلى فى مادة علم النفس ومقياس الأكاء الاجتماعى. r- عرض الادوات على السادة المحكمين. ع - التحقق من الخصائص السيكومترية لادوات الدراسة وتعديلها فى ضوء ما توصلت اليه وفى توفين ضوء تعديلات السادة المحكمين.

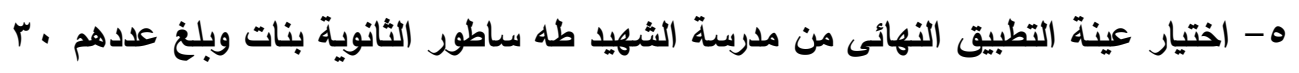
طالبة צ- تم التطبيق البرنامج فى r أسبوع بواقع جلستين أسبوعيا.

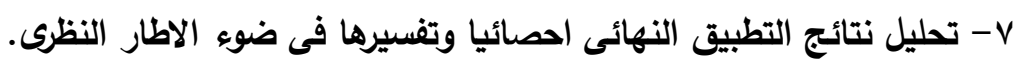




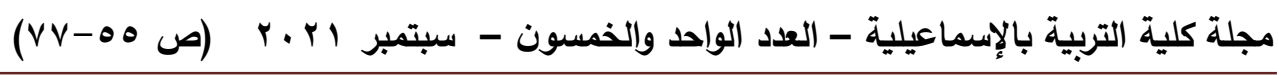
المعوقات التى واجهت تطبيق الاجراءات ا - لم يكفى وقت الحصة المدرسية وهى ه ؛ دقيقة لتطبيق جلسات البرنامج، لذا تم تغيير وقت

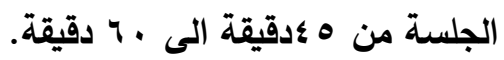
r - عدم انتظام طلاب الصف الثالث الثانوى فى الحضور فى معظم مدارس الجمهورية، لذا تم اختيار مدرسة الثهيد طة ساطور الثانوية بنات بالتحديد لانتظام الطالبات فى الداسة.

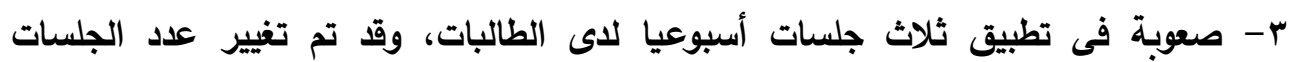
الاسبوعية للبرنامج من ثلاث جلسات فى الاسبوع الى جلستان أسبوعيا بناءا على طلب الطالبات. ـ - صعوبة تجميع طلاب المجموعة التجريبية للبرنامج، حيث أنهم من ست فصول مختلفة، مما استدعى الحاجة الى مساعدة ادارة المدرسة فى تذليل هذة الصعوبة، وقد قامت الاخصائية النفسية طواعية بهذا الدور خلال فترة البرنامج. ه - الحاجة الى أدوات و تجهيزات مسبقة و الى مكان مجهز و محدد لتطبيق جلسات البرنامج. צ- لم يتمكن الباحث من القياس التبعى بسبب صعوبات تتعلق بغياب الطالبات وعدم الحضور للمدرسة بعد الفصل الدراسى الثانى ولأن أداء التحصيل الدراسى فى نهاية الثانوية العامة وليست هناك إختبارات أخرى. نتائج الاراسة ومناقشتها وتفسيرها تحليل وتفسير النتائج لتحقيق اهداف الدراسة بيين جدول (V) حساب المتوسطات والانحرافات المعيارية ومعاملات الالتواء لارجات أبعاد مقياس الأكاء الاجتماعى والدرجة الكلية

\begin{tabular}{|c|c|c|c|c|c|c|}
\hline التفرطح & الالتواء & الانعراف & الوسيط & المستوسط & & البعد \\
\hline |דוT, & $\cdot, r v$ & $r, r q$ & 9 & $9, \wedge 9$ & قبلى & \multirow{2}{*}{ الموقفى } \\
\hline • & $\cdot, r_{0}$ & $r, I V$ & 19 & 19,100 & بعدى & \\
\hline$\cdot, r \circ \wedge$ & $\cdot, \cdot \leq \leqslant$ & r, ro & 9 & 9,1 & قبلى & \multirow{2}{*}{ والتأثضر } \\
\hline$\cdot, r \otimes V$ & $\cdot, \leqslant 1$ & $r, 1 T$ & 19 & $19, \wedge 1$ & بعدى & \\
\hline • . & צ & $r, r_{1}$ & $\wedge$ & $\Lambda, \vee \vee$ & قبلى & \multirow{2}{*}{ الوضوح } \\
\hline$\cdot, r \circ \wedge$ & $\cdot, 1 \cdot 1$ & $r, 0$ & 19 & $19, r v$ & بعدى & \\
\hline$\cdot, r \otimes V$ & $\cdot, r \wedge$ & $r, 1 r$ & 9 & 9,71 & قبلى & \multirow{2}{*}{ التعاطف } \\
\hline . & $\cdot r$ & $r, r$ & 19 & $19, v$ & بعدى & \\
\hline
\end{tabular}


أثر استخدام استراتيجية لعب الادوار على تنمية الأكاء الاجتماعى --- محمد أحمد محمد سليم

\begin{tabular}{|c|c|c|c|c|c|c|}
\hline$\cdot, r \circ \Lambda$ & $\cdot, \cdot \vee \wedge$ & Y,04 & 9 & $q, Y$. & قبلى & المهارات \\
\hline$\cdot, r \otimes V$ &., $1 \pi$ & $r, r V$ & 19 & $19, \pi \mid$ & بعدى & الاجتماعية \\
\hline . & $\cdot, \cdot r$ & $11, \varepsilon$ & 9. & $7 ., \leqslant 1$ & قيلى & الارجة \\
\hline ., Yצ. &.,$\cdot \wedge$ & o, & $9 \leqslant$ & $9\{, \wedge \uparrow$ & بعدى & الكلية \\
\hline
\end{tabular}

يتضح من جدول (V) ان التوزيع التكرارى لمتغيرات الدراسة يقترب من الاعتدالية حيث أن قيم المتوسط تقترب من الوسيط لارجات أبعاد مقياس الأكاء الاجتماعى والارجة الكلية، ومعاملات

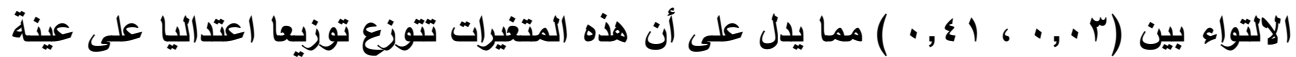

الاراسة

التجقق من نتائج الفرض وتفسيرها

أولاً : ينص الفرض على أنة " توجد فروق دالة بين متوسطات درجات المجموعة التجريبية والمجموعة الضابطة فى القياس البعدى لمقياس الأكاء الاجتماعى لصالح المجموعة التجريبية للتحقق من صحة الفرض تم استخدام اختبار ت للالالة الاحصائية، كما هو موضح بالجدول

جدول (^) متوسط درجات طلاب المجوعتين والانحرافات المعيارية وقيمة ت لالالة الفروق بين المجموعتين فى أبعاد مقياس الأكاء الاجتماعى.

\begin{tabular}{|c|c|c|c|c|c|c|}
\hline حجم التأثير & عند ا مستوى الالالة & قيمة & الانحراف & المتوبط & المجموعة & المتغير \\
\hline \multirow{2}{*}{$\begin{array}{c}\% 74 \\
\text { عال } 7\end{array}$} & \multirow{2}{*}{ دال عند } & \multirow{2}{*}{$\bullet, r r$} & ש צ & Q, \० & الضابطة ن =0 1 & \multirow{2}{*}{ الوعى } \\
\hline & & & $r, I V$ & 19,100 & التجريبية =0 1 & \\
\hline \multirow{2}{*}{$\begin{array}{r}\% \vee v \\
\text { عال }\end{array}$} & \multirow{2}{*}{ 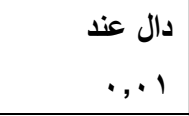 } & \multirow{2}{*}{$q, r$} & $\varepsilon, \leqslant 0$ & $\Lambda, \vee \uparrow$ & الضابطة ن =0 1 & \multirow{2}{*}{ الحضور } \\
\hline & & & $r, I r$ & 19,11 & التجريبية =0 & \\
\hline$\% \curlyvee \wedge$ & \multirow{2}{*}{ دال عـد } & \multirow{2}{*}{$0, T \vee$} & $\varepsilon, \diamond \vee$ & $\Lambda, \bullet$ & الضابطة ن =0 1 & \multirow{2}{*}{ الوضوح } \\
\hline عال & & & $r, 0$ & $19, r v$ & التجريبية =0 10 & \\
\hline$\% 7 v$ & \multirow{2}{*}{ دال عند } & \multirow{2}{*}{$0, \leqslant \leqslant$} & $\varepsilon, T V$ & $9, \leqslant r$ & الضابطة ن =0 1 & \multirow{2}{*}{ التعاطف } \\
\hline عال & & & $r, r$ & $19, v$ & التجريبية =0 1 & \\
\hline$\% \vee \leq$ & \multirow{2}{*}{ 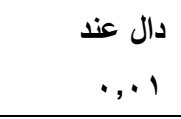 } & \multirow{2}{*}{$9, \cdot$} & $\varepsilon, \vee r$ & $9,1 \leq$ & الضابطة ن =0 10 & \multirow{2}{*}{ الاجهارات } \\
\hline عال & & & $r, r v$ & $19, r \mid$ & التجريبية =0 & \\
\hline $\begin{array}{c}\% \vee \wedge \\
\text { عال }\end{array}$ & دال عند & $9, \varepsilon$ & $1 Y, 7$ & $0 V, T \leq$ & الضابطة ن =0 1 & الارجة \\
\hline
\end{tabular}




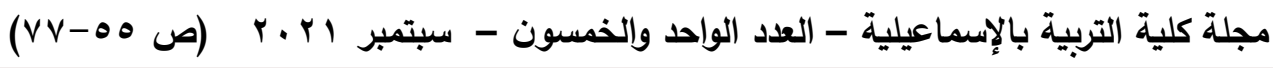
من خلال قيم جدول (^) يتضح ما يلى : - هناك فروق دالة بين متوسطى درجات المجموعتين التجريبية والضابطة فى القياس البعدى

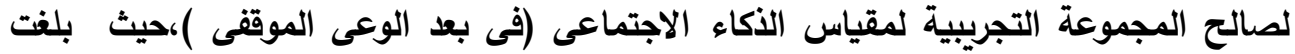

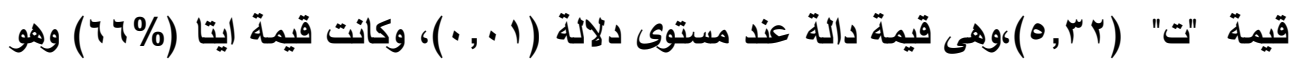
تأثير كبير . - هناك فروق دالة بين متوسطى درجات المجموعتين التجريبية والضابطة فى القياس البعدى

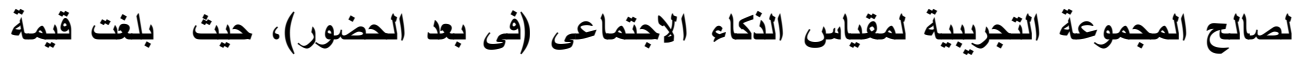

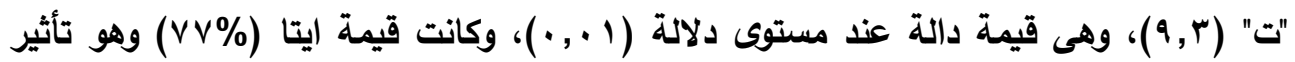
كبير

- هناك فروق دالة بين متوسطى درجات المجموعتين التجريبية والضابطة فى القياس البعدى

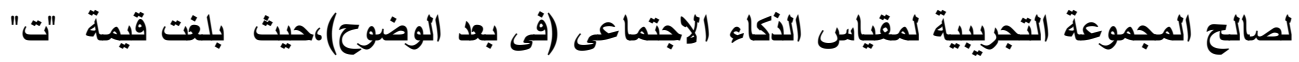

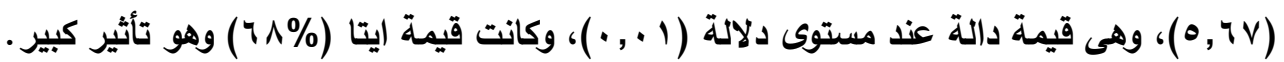
- هناك فروق دالة بين متوسطى درجات المجموعتين التجريبية والضابطة فى القياس البعدى

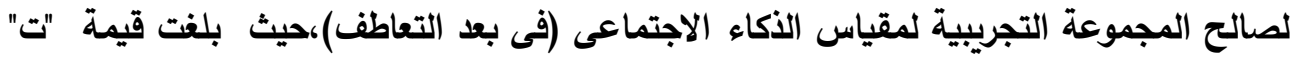

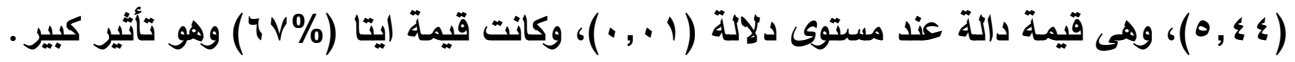
- هناك فروق دالة بين متوسطى درجات المجموعتين التجريبية والضابطة فى القياس البعدى دائات

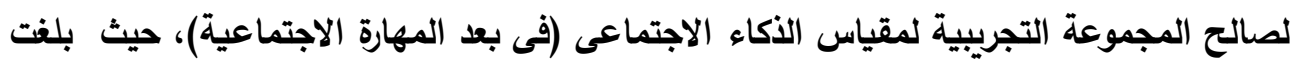

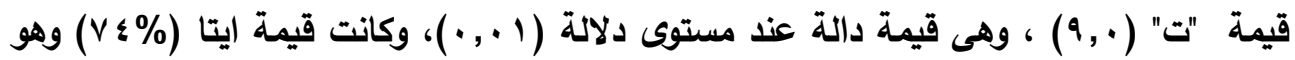
تأثير كبير. - هناك فروق دالة بين متوسطى درجات المجموعتين التجريبية والضابطة فى القياس البعدى

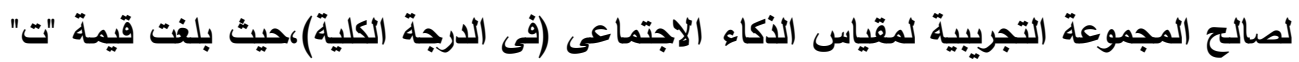

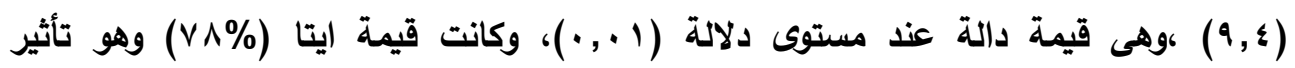
كبير،ويظهر التأثير العالى للجاتب السلوكى لاى الطالبات المتمثل فى أبعاد الحضور والتأثير، المهارات الاجتماعية، التعاطف عن الجانب المعرفى المتمثل فى الوعى الموقفى والوضوح.

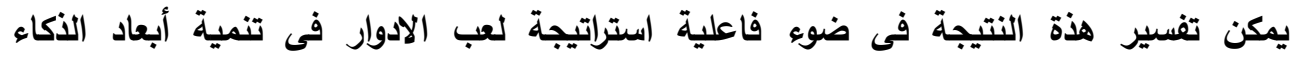

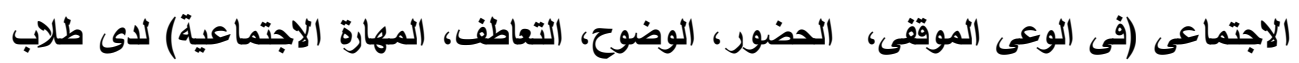

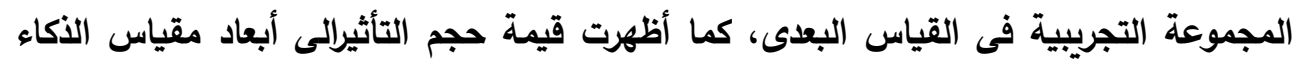
الاجتماعى على تأثير كبير الى استراتيجة لعب الادوار لاى طلاب المجموعة التجريبية فى القياس التياس 
أثر استخدام استراتيجية لعب الادوار على تنمية الأكاء الاجتماعى --- محمد أحمد محمد سليم

البعدى فى أبعاد الذكاء الاجتماعى، ويتفق ذلك مع نتيجة دراسة كلا من: دراسة ياسمين الصايغ

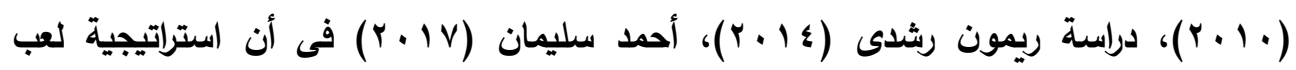

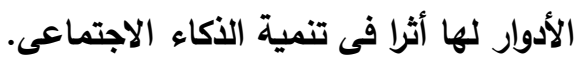
المناقشة و التعليق

من خلال عرض النتائج وتحليلها، وبالرجوع الى الاطار النظرى والدراسات السابقة لاحظ الباحث أن استراتيجية لعب الادوار أتاحت لاى الطالبات القدرة على محاكاة الواقع من خلال المواقف التى كانوا يتعرضن لها اثناء الجلسات مما جعل لايهن القدرة على التعايش مع المواقف التى يتعرضن

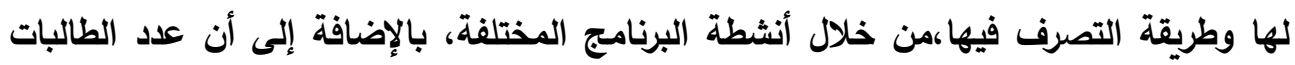
كان صغيرا، مما اتاح الفرصة للعمل بروح الفريق الواحد والقدرة على التواصل والمشاركة وادارة الوقت وإتخاذ القرار والقيادة، كما أن التنوع فى استخدام انشطة البرنامج يجذب اهتمام الطالبات ويذهب الملل ويكثف عن مواهب الطالبات، ولها أثر فى تحفيز الطالبات وجعلهن يشعرون أن

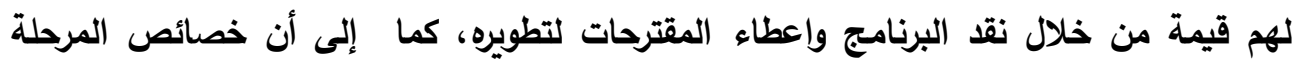
العمرية التى تتميز بالاتجاه نحو ممارسة أدوار اجتماعية وتكوين مهارات اجتماعية مثل تكوين صداقات والتواصل مع الاخرين بفعالية قد ساعد على تحسن الطالبات فى بعض أبعاد لبعاد مقياس الأكاء الاجتماعى من ( الحضور والتأثير، والمهارات الاجتماعية والتعاطف) على سلوكيات الطالبات وتعاملتهن اليومية مما انعكس على قرة الطالبات فى تكوين صداقات قوية لايهن

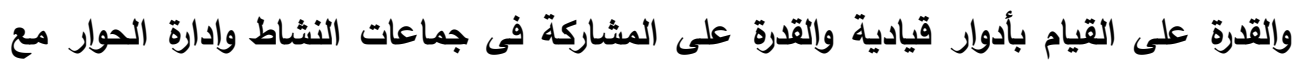
الآخرين والرغبة فى زيارة الأصدقاء والأقارب بثكل دورى باضافة الى حب تعليم الآخرين. التوصيات والبحوث المقترحة التوصيات بناء على النتائج التى خلصت الدراسة اليها، تقدم الدراسة عدة توصيات لتعزيز استخدام بعض استراتيجيات التعلم النشط فى تحسين التحصيل الدراسى لاى طالبات مادة علم النفس بالصف الثالث الثانوى و تنمية الأكاء الاجتماعى لايهن: 1 - التدريب معلى المرحلة الثانوية على تنفيذ استراتيجيات التعلم النشط لتحسين نواتج التعلم المعرفية والوجدانية والمهاريـة. ץ - تنويع الأنشطة التعليمية داخل الحصص ليزيد من دافعية الطالبات للتعلم. 


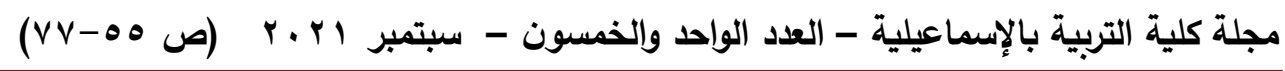
ب- استخدام استراتيجيات التعلم النشط لتنظيم مقرر مادة علم النفس واعطاء الكثير من الأمثلة الثارحة التى تسهم فى الاحتفاظ بالمادة. ع - اجراء المزيل من الدراسات حول تنمية الذكاء الاجتماعى باستخدام استراتيجية لعب الادوار، لانها تحتاج لمزبد من الدراسات. ه- اجراء المزبد من الدراسات حول تنمية الأكاء الاجتماعى باستخدام استراتيجيات تعلم أخرى لاى فئات عمرية ودراسية مختلفة. البحوث المقترحة

1 - فعالية استراتيجيات التعلم النشط فى تحسين الابداع الجماعى لاى طالبات المرحلة الثانوية. r- فعالية بعض استراتيجيات التعلم النشط (فكر -شارك -زاوج -عظم السمكة-التخيل الموجة) فى تحسين التحصيل الدراسى لمادة علم النفس لاى طلاب الصف الثانى الثانوي منففضى التحصيل. ب- فعالية برنامج مقترح لتدريب معلمى علم النفس بالمرحلة الثانوية لتنمية الذكاء الاجتماعى لاى طلاب المرحلة الثانوية. 
أثر استخدام استراتيجية لعب الادوار على تنمية الأكاء الاجتماعى --- محمد أحمد محمد سليم

\section{المراجع}

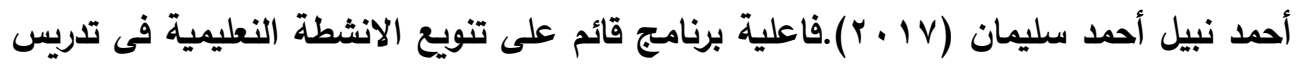
علم الاجتماع لتنمية الأكاء الاجتماعى لاى طلاب المرحلة الثانوية. مجلة الجمعية التربوية التماية للدراسات الاجتماعية. رسالة دكتوراة غير منشورة، قسم مناهج وطرق تدريس المواد

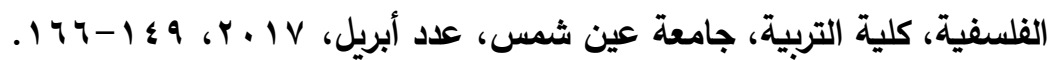

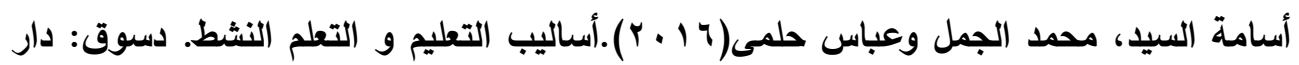

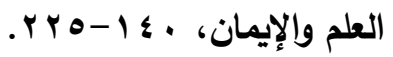

ريمون اليعازد رشدى (؟ 1 ب). برنامج قائم على الانثطة لتنمية الأكاء الاجتماعى لاى تلاميذ

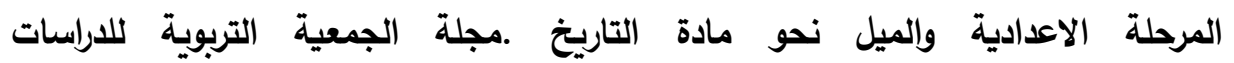

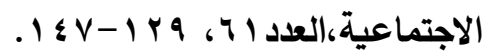

سميرة عطية العريان (· • (Y). عادات العقل و مهارات الذكاء الإجتماعى فى القرن الحادى

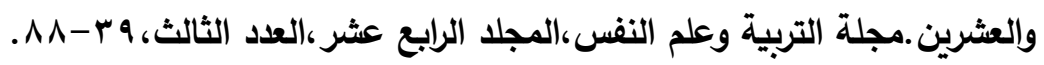

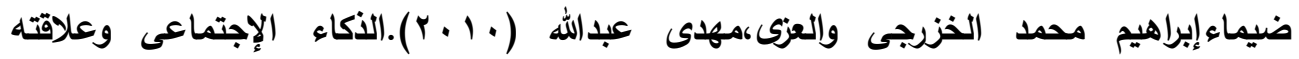
بالتحصيل الدراسى لدى طالبات بمعهد إعداد المعلمات. مجله ديالى للبحوث الإنسانيه

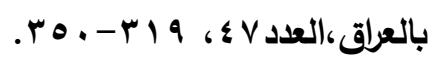

طارق عبدالرؤف عامر، ايهاب عيسى المصرى (r ب ـ ب).التعلم النشط، مؤسسة طيبة للنشر. القاهرة، 1-1.

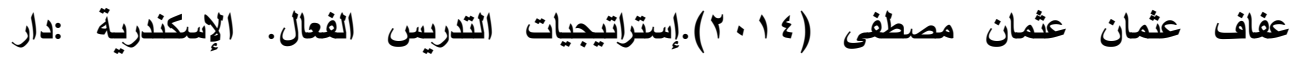

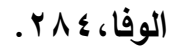

فتحى محمد خليل الشرقاوى (^ . . ب). تأثير أنماط نظم المعلومات الإجتماعية و مستوياتها على الأكاء الإجتماعى لتلاميذ الصف الثانى الإعدادى.رسالة ماجستير غير منشورة،علم النفس

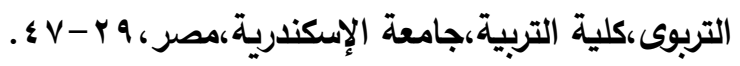

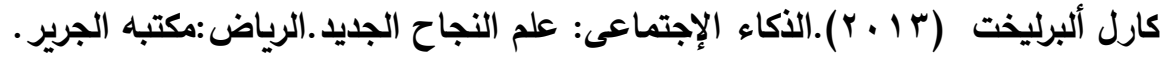

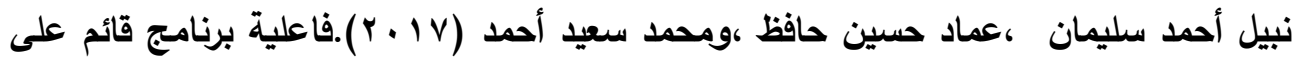
تنويع الأنشطة التعليمية فى تدريس علم الإجتماع لتنمية الذكاء الإجتماعى لاى طلاب

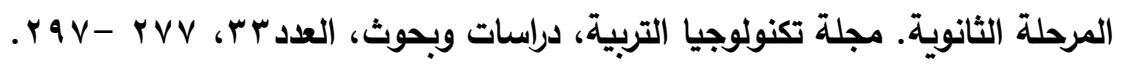




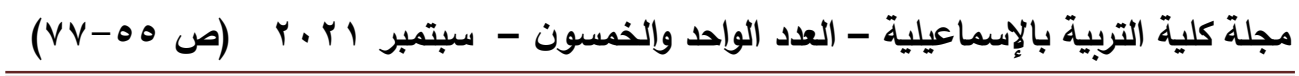

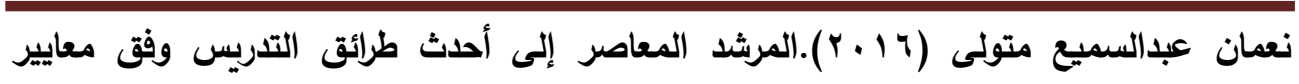

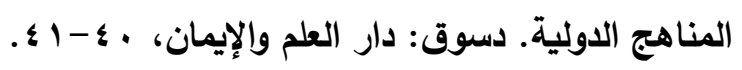

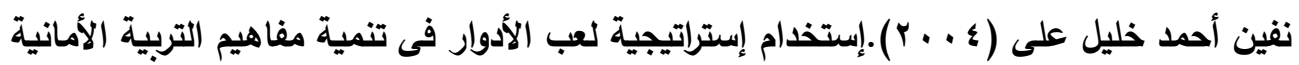

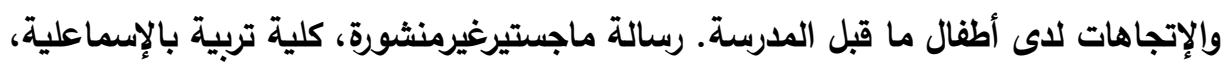
جامعة قناة السويس، مصر .

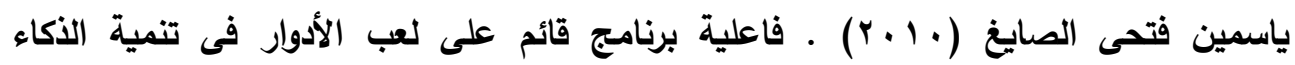

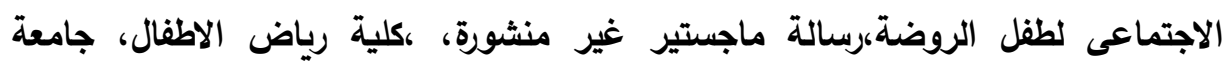

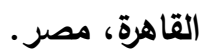

MCCaRTHy,j. \& aNyeux, L., (2000). Active learning techniques versus traditional teeching Styles: two Experiment from History and political science Innovative Higher Educetion 24(4),279-294..

Silvera , D. H., Martinussen, M., \& Dahl, T. I. (2001). the troms social intelligence scale, a self-report measure of social intelligence. Scandinavian Journal of Psychology, 42,313-319. 
أثر استخدام استراتيجية لعب الادوار على تنمية الذكاء الاجتماعى --- محمد أحمد محمد سليم

الملخص

يهرف البحث الحالي إلى التعرف على أثر برنامج قائم على إستراتيجية لعب الادوار فى تنمية

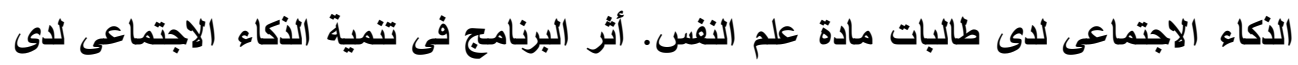
طالبات الصف الثالث الثانوى فى مادة علم النفس. أقتصر البحث الحالي على: تقتصر الدراسة على موضوعها على إستخدام إستراتيجية لعب الادوار لتنمية الأكاء الإجتماعى، وتم التطبيق

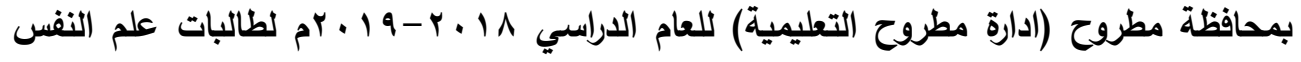

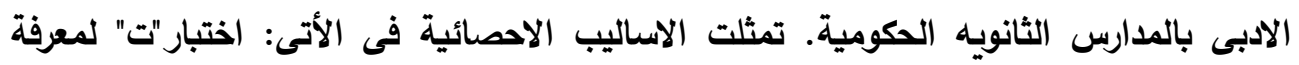

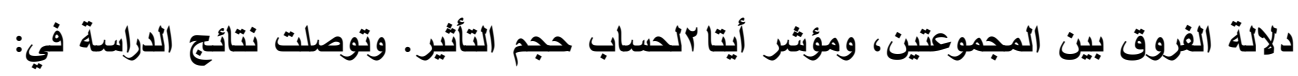
توجد فروق دالة بين متوسطات درجات المجموعة التجريبية والمجموعة الضابطة فى القياس البعدى لمقياس الأكاء الاجتماعى لصالح المجموعة التجريبية.

\begin{abstract}
The researcher used the quasi-experimental design to determine The Effect of Using Role Playing Strategies on Improving Developing Social Intelligence. Main sample: The study sample was consisted of $(n=30)$ females students from females secondary sattor school in Psychology at Marsa Matrouh Educational Directorate, Matrouh Governorate.

Results of the study: There are Statistically Significant differences between the mean scores of the experimental and control groups in the post social intelligence scale of the experimental group.
\end{abstract}

